\section{Supported gold catalysts for selective hydrogenation of 1,3-butadiene in the presence of an excess of alkenes}

\section{Antoine Hugon, Laurent Delannoy, Catherine Louis*}

Laboratoire de Réactivité de Surface, UMR 7609 CNRS, Université Pierre et Marie Curie-Paris 06, 4 place

Jussieu, 75252, Paris, Cedex 05, France

* corresponding author

e-mail: catherine.louis@upmc.fr

\begin{abstract}
Supported gold catalysts were investigated in the selective gas phase hydrogenation of 1,3-butadiene in an excess of propene $(0.3 \%$ butadiene, $30 \%$ propene and $20 \%$ hydrogen), in order to simulate the process required for the purification of industrial alkenes streams to prevent poisoning of the polymerisation catalysts used for polyalkene production. Gold catalysts containing small gold particles (between 2 to $5 \mathrm{~nm}$ in average) are less active than commercial palladium catalysts, but they are much more selective. Under our experimental conditions, $100 \%$ of butadiene can be converted at $\sim 170^{\circ} \mathrm{C}$ into $100 \%$ butenes with 1-butene as the main product, and with only very small amount of alkanes formed $(\sim 100$ ppm). The absence or presence of propene does not drastically modify the rate of hydrogenation of butadiene.

Parameters directly related to the nature of the gold catalysts were also investigated. For a given preparation method (deposition-precipitation with urea (DPU)), gold particle size and gold loading, the nature of the oxide support (alumina, titania, zirconia, ceria) does not influence the gold reactivity. The variations of gold particle size and gold loading do not induce changes in the TOF (expressed per surface gold atoms). The method of preparation has an influence when it leaves chlorine in the samples (impregnation in excess of solution and anionic adsorption). In such a case, the gold catalysts are less active.
\end{abstract}

\section{Keywords}

gold, ceria, titania, alumina, zirconia, reducibility, hydrogenation, butadiene, propene, butene, DRIFTS, TPR, TEM, catalysis

\section{Introduction}

Light alkenes produced by catalytic cracking of petroleum contain significant amounts of alkadienes or alkynes (1). Typically, the ethylene cuts contain 0.5 to $3 \%$ of acetylene and the propene cuts 2 to $8 \%$ of propyne and propadiene. Before subsequent processing, these raw streams must be purified. For instance, for further polymerisation processing, the level of impurity in alkadienes or alkynes must be as low as 10 ppm (1). Therefore, these molecules must be selectively converted to alkenes without further hydrogenation of the alkene stream. Palladium is so far regarded as the unique metal, which has the commercial ability to selectively hydrogenate alkadienes or alkynes in an excess of alkenes, and it is used in industry for gas- and liquid-phase selective hydrogenation. However oligomers ('green oil') form during hydrogenation over supported Pd catalyst, which shortens the recycle time and life of the industrial catalyst. Moreover, if palladium is highly selective when the concentration of impurities is still high, in contrast, for ultimate purification and elimination of traces of alkadienes or alkynes, i.e., at high conversion, alkenes start to be hydrogenated, and palladium catalysts are not selective enough. To limit these problems, promoters such as $\mathrm{Ag}, \mathrm{Co}, \mathrm{Cu}, \mathrm{Cr}$, alkali metals, lead acetate and metal oxides are added to Pd catalysts. For instance, the addition of a group I B metal to Pd catalysts increases the selectivity of acetylene hydrogenation to ethylene, reduces the yield of 'green oil', and improves the properties of traditional Pd catalysts (2).

On the other hand, the few studies performed over supported gold catalysts showed that gold was highly efficient for selectively hydrogenating alkadienes or alkynes at high conversion, even though gold was not as active as palladium (3). The first studies were reported by Bond and Wells in the seventies $(4,5)$, i.e., almost 15 years before the discovery by Prof. Haruta and his team that gold catalysts were amazingly active in CO oxidation at room temperature or below RT, providing that small gold particles could be prepared. Hence, the first studies published were performed with catalysts containing large gold particles (up to $50 \mathrm{~nm}$ ). In spite of that, Bond and Wells reported that gold supported on alumina and boehmite (hydrated alumina) was able to selectively hydrogenate 1,3-butadiene into butenes without butane formation between 130 and $260^{\circ} \mathrm{C}$. More recently, Okumura and Haruta (6) reported a study performed on a series of gold catalysts supported on various supports (alumina, titania and silica), prepared by different methods and containing different average gold particle sizes (from 2.5 to $37 \mathrm{~nm}$ ). All the catalysts were able to selectively hydrogenate butadiene into butenes with $100 \%$ selectivity, and the reaction of 1,3butadiene hydrogenation over Au catalysts was found almost 
insensitive to the size of the gold particles and the nature of the oxide supports.

Selective hydrogenation of acetylene and ethylene were also performed over gold catalysts containing small gold particles (3.8 nm in $\mathrm{Au} / \mathrm{Al}_{2} \mathrm{O}_{3}$ prepared by depositionprecipitation) (7). Below $250^{\circ} \mathrm{C}$, in batch reactor, gold was able to hydrogenate acetylene into ethylene with 100\% selectivity. The same type of results was then reported for $\mathrm{Au} / \mathrm{TiO}_{2}$ in a continuous flow reactor (2). The catalyst containing large gold particles ( $30 \mathrm{~nm}$, impregnation method) showed much lower activity than that containing small particles (4.7 nm, grafting of a gold phosphine precursor), which showed $100 \%$ conversion at $180^{\circ} \mathrm{C}$ with a selectivity higher than $90 \%$. A paper on selective hydrogenation of propyne was also published (8), showing again excellent selectivities with $\mathrm{Au} / \mathrm{TiO}_{2}\left(\mathrm{~d}_{\mathrm{Au}}=3.7 \mathrm{~nm}\right)$ and $\mathrm{Au} / \mathrm{Fe}_{2} \mathrm{O}_{3}$ catalysts $\left(\mathrm{d}_{\mathrm{Au}}=3.7 \mathrm{~nm}\right)$.

Only one study was performed in conditions closer to those of purification. This was the hydrogenation of propyne in presence of propene (propyne/propene/ $\mathrm{H}_{2}$ ratios of $1 / 1 / 3$ ) in a continuous flow reactor over a $\mathrm{Au} / \mathrm{CeO}_{2}$ catalyst prepared by deposition-precipitation ( $\left.d_{A u}=4 \mathrm{~nm}\right)$ (9). Perez-Ramirez et al. observed high selectivity to propene $\left(90 \%\right.$ at $\left.300^{\circ} \mathrm{C}\right)$ even at high conversion (90\%). The presence of additional propene led to a slightly higher selectivity, but also to a slightly lower conversion.

The goal of the present study was to explore the properties of gold catalysts in the reaction of selective hydrogenation of an alkadiene in the presence of an excess of alkenes in conditions close to the real conditions of purification, i.e., with an alkene/alkadiene ratio of 100. In the study of Perez-Ramirez et al. (9) reported above, the propene/propyne ratio was equal to 1 . Among the model reactions of selective hydrogenation of alkynes and alkadienes in alkenes, we chose that of 1,3butadiene, i.e. the issue of the purification of a $\mathrm{C}_{4}$ cut, because it gives four different products (three butenes and butane), with 1-butene as the most desirable product (10), and therefore allows the study of both activity and selectivity issues. In order to be able to easily distinguish the alkane arising from the total hydrogenation of 1,3-butadiene from that arising from the hydrogenation of the alkene in excess, we chose to study the reaction of selective hydrogenation of 1,3-butadiene in an excess of propene. The choice was based on the hypothesis that the reactivity of propene was the same as that of butenes; this hypothesis was a posteriori experimentally justified by our results. In the present paper, parameters directly related to the nature of the catalysts (nature of the support, gold particle size, gold loading, method of preparation) were investigated, as well as parameters arising from the reaction mixture (reactant concentrations).

\section{Experimental}

\section{A. Catalyst preparation}

Titania (P25, Degussa, $50 \mathrm{~m}^{2} \cdot \mathrm{g}^{-1}, 70 \%$ Anatase, 30\% Rutile), ceria (HSA5, Rhodia, $200 \mathrm{~m}^{2} \cdot \mathrm{g}^{-1}$ ), alumina (AluC Degussa, 110 $\mathrm{m}^{2} \cdot \mathrm{g}^{-1}, \quad \delta$-type) and zirconia (Rhodia, $21 \mathrm{~m}^{2} \cdot \mathrm{g}^{-1}$ ) were used as supports, and $\mathrm{HAuCl}_{4}, 3 \mathrm{H}_{2} \mathrm{O}$ (Acros Chemicals) as gold precursor. Before use, $\mathrm{CeO}_{2}$ and $\mathrm{ZrO}_{2}$ were calcined under air at $500^{\circ} \mathrm{C}$.

The catalysts were prepared by three different methods: deposition-precipitation with urea (DPU) as described previously $(11,12)$, impregnation in excess of solution (IE) and anionic adsorption (AA) (13). For each preparation, $3 \mathrm{~g}$ of support and $60 \mathrm{mg}$ of $\mathrm{HAuCl}_{4}, 3 \mathrm{H}_{2} \mathrm{O}$ were used, in order to achieve a nominal gold loading of $1 \mathrm{wt} \%$.

The catalysts were prepared by deposition-precipitation with urea (DPU) as described previously $(11,12)$ using $\mathrm{TiO}_{2}$, $\mathrm{CeO}_{2}, \mathrm{Al}_{2} \mathrm{O}_{3}$ and $\mathrm{ZrO}_{2}$ as supports. A $300 \mathrm{~mL}$ solution containing $\mathrm{HAuCl}_{4}\left(5.10^{-4} \mathrm{M}\right), 0.9 \mathrm{~g}$ of urea $\left(\mathrm{C}_{\text {urea }} \sim 100 \times \mathrm{C}_{\mathrm{Au}}\right)$ and the support $(3 \mathrm{~g})$ was prepared, stirred at $80^{\circ} \mathrm{C}$ for $16 \mathrm{~h}$ in a dark, closed reactor. It is worth noting that, as urea is a potential nitrogen-containing ligand for gold, some care must be used regarding the possible formation of fulminating gold $(3,14)$. The solid was separated by centrifugation, washed four times with deionised water (with centrifugation between each washing). After the third washing, a few drops of silver nitrate were added to the washing solution, and did not show any $\mathrm{AgCl}$ precipitation. The samples were then dried under vacuum at RT for $12 \mathrm{~h}$, resulting in "as-prepared" samples. For comparison, one $\mathrm{Au} / \mathrm{Al}_{2} \mathrm{O}_{3}$ sample was kept unwashed.

$\mathrm{Au} / \mathrm{Al}_{2} \mathrm{O}_{3}$ samples were prepared by impregnation in excess of solution (IE). $3 \mathrm{~g}$ of support were wetted with $24 \mathrm{~mL}$ of water. Then, a $6.0 \mathrm{~mL}$ solution of $\mathrm{HAuCl}_{4}, 3 \mathrm{H}_{2} \mathrm{O}$ (60 mg) were added drop by drop under vigorous stirring then continuously mixed for an additional hour in the dark. Then the mixture was dried with a rotavapor at $80^{\circ} \mathrm{C}$ under vacuum for one hour.

$\mathrm{Au} / \mathrm{Al}_{2} \mathrm{O}_{3}$ samples were prepared by anionic adsorption (AA). A $290 \mathrm{~mL}$ aqueous solution containing $3 \mathrm{~g}$ of support was heated to $80^{\circ} \mathrm{C}$. Then, a $6.0 \mathrm{~mL}$ solution of $\mathrm{HAuCl}_{4}, 3 \mathrm{H}_{2} \mathrm{O}$ (60 mg) were added drop by drop under vigorous stirring then continuously mixed for an additional hour in the dark. The solid was separated by centrifugation, washed four times, and dried the same way as the DPU samples.

After drying, all the samples were stored at RT under vacuum in a desiccator, away from light in order to prevent any uncontrolled reduction of gold (15). The colour of the catalysts depended on both the nature of the support (orange with alumina, yellow with ceria (like ceria) and white for zirconia and titania for DPU samples) and the preparation method (with alumina, orange by DPU, and yellow for IE and AA).

Before characterisation and reaction, the gold catalysts were reduced under $\mathrm{H}_{2}$ at $300^{\circ} \mathrm{C}\left(100 \mathrm{~mL} \cdot \mathrm{min}^{-1}, 2^{\circ} \mathrm{C} \cdot \mathrm{min}^{-1}\right.$, from RT to $300^{\circ} \mathrm{C}$, then for $2 \mathrm{~h}$ at $300^{\circ} \mathrm{C}$ ). In some cases, thermal treatment was performed at higher temperature or under air. Upon reduction, the colour of the samples changes: deep violet for titania, pink purple for alumina, black-brown for ceria and purple for zirconia. 


\section{B. Techniques of characterisation}

Chemical analyses of $\mathrm{Au}, \mathrm{Cl}$ and metal cation of the support were performed by inductively coupled plasma atom emission spectroscopy at the CNRS Center of Chemical Analysis (Vernaison, France). The Au weight loading of the samples was expressed in gram of Au per gram of sample: wt\% Au = $\left[\mathrm{m}_{\text {Au }} /\left(\mathrm{m}_{\text {Au }}+\mathrm{m}_{\text {support }}\right)\right] \times 100$.

The dried samples $(150 \mathrm{mg}$ ) were reduced by temperature programmed reduction (TPR) in a quartz gas flow reactor, from room temperature to $600^{\circ} \mathrm{C}$, with a heating rate of $7.5^{\circ} \mathrm{C}$. $\mathrm{min}^{-1}$, under a stream of $5 \% \mathrm{v} / \mathrm{v} \mathrm{H}_{2}$ in argon (total flow rate $=25 \mathrm{~mL}$. $\mathrm{min}^{-1}$ ) at atmospheric pressure. The amount of the hydrogen consumed was measured with a thermal conductivity detector.

TEM analysis was performed using a JEOL JEM-100 CX ॥ microscope operating at $100 \mathrm{kV}$. Gold particle size measurement was performed using ITEM software on digitized micrographs. Note that particles were measured one by one and not automatically. The limit of size detection was about $1 \mathrm{~nm}$, but it was easier to measure gold particles on titania than on alumina. It was not possible to measure them on ceria because of the too low contrast between ceria and gold particles due to the high atomic number of $\mathrm{Ce}$ and the high surface area of ceria (16). The average metal particle sizes $d_{A u}$ were determined from the measurement of at least 300 particles. $d_{\text {Au }}$ was calculated using the following formulaes: $d_{\text {Au }}=\sum n_{i} d_{i}^{3} / \sum n_{i} d_{i}^{2}$ (volumic mean) and $d_{A u}=\Sigma n_{i} d_{i} /$ $\Sigma n_{\mathrm{i}}$ (arithmetic mean) where $\mathrm{n}_{\mathrm{i}}$ is the number of particles of diameter $\mathrm{d}_{\mathrm{i}}$.

XRD analysis was carried out with a Siemens D500 diffractometer with $\mathrm{Cu} \mathrm{K}_{\alpha}$ radiation.

Infrared spectroscopy was performed with an IFS 66V Bruker spectrometer using a DRIFTS cell (collector from Spectratech). The sample compartment of the cell was filled with the asprepared gold sample ( $\sim 10 \mathrm{mg})$, which was reduced in situ from room temperature to $300^{\circ} \mathrm{C}$, with a heating rate of $2^{\circ} \mathrm{C}$. $\mathrm{min}^{-1}$, under a stream of $5 \% \mathrm{v} / \mathrm{v} \mathrm{H}_{2}$ in argon (total flow rate $=50$ $\mathrm{mL} \cdot \mathrm{min}^{-1}$ ) then for $30 \mathrm{~min}$ at $300^{\circ} \mathrm{C}$. The cell was cooled to RT, then purged with $\mathrm{He}$ before introduction of a mixture containing of $1 \% \mathrm{v} / \mathrm{v} \mathrm{CO}$ in He. A reference spectrum was recorded in $\mathrm{He}$, and the intensity of the spectrum in $\mathrm{CO} / \mathrm{He}$ atmosphere was expressed as $\log \left(I_{\text {co }} / l_{\text {ref }}\right)$.

\section{Catalytic reaction}

The hydrogenation reaction was carried out with $100 \mathrm{mg}$ of catalyst (sieve fraction, $125-200 \mu \mathrm{m}$ ) in a plug flow microreactor in pyrex (4 mm of internal diameter). Except when specifically mentioned, the catalysts were activated in situ, under pure $\mathrm{H}_{2}\left(100 \mathrm{~mL} \cdot \mathrm{min}^{-1}\right)$ from RT to $300^{\circ} \mathrm{C}\left(2^{\circ} \mathrm{C}\right.$. $\mathrm{min}^{-1}$ ) and kept about $30 \mathrm{~min}$ at $300^{\circ} \mathrm{C}$. Then, the catalysts were cooled to room temperature under pure $\mathrm{H}_{2}$, and the reaction mixture consisting of $0.3 \%$ butadiene, $30 \%$ propene and $20 \%$ hydrogen was introduced with a flow rate of 50 $\mathrm{mL} \cdot \mathrm{min}^{-1}$ (NTP conditions), which corresponds to a space velocity of $30000 \mathrm{~mL} \cdot \mathrm{g}^{-1} \cdot \mathrm{h}^{-1}$ (GHSV $\left.=20000 \mathrm{~h}^{-1}\right)$. The catalysts were heated under this gas mixture at a rate of $1^{\circ} \mathrm{C} \cdot \mathrm{min}^{-1}$, up to $300^{\circ} \mathrm{C}$. Gas analysis at the outlet of the reactor was performed every $15 \mathrm{~min}$, i.e., every $15^{\circ} \mathrm{C}$, between 30 and $300^{\circ} \mathrm{C}$. It was checked that with the slow heating rate chosen, the reaction rate was at the equilibrium, at least at low temperatures since deactivation occurs at higher temperature. When $300^{\circ} \mathrm{C}$ was reached, the reactor was gradually cooled, and other measurements were performed at decreasing temperature, $260,220,200,180,160,140$ and $120^{\circ} \mathrm{C}$ to evaluate possible deactivation of the catalysts. The analysis of reaction products was effected by gas chromatography (Perichrom PR 2100, FID detector) using a 7.5 m column (1/8 inch) filled with sebaconitrile 25\% Chromosorb PAW 80/100 Mesh). Retention times and sensitivity factors for the reactants and products were calibrated using several gas mixtures. Software Winilab 4.0 was used for data acquisition and extraction of the concentrations of the different gases detected. Titania and alumina alone did not show activity, only $20 \mathrm{ppm}$ of butadiene being hydrogenated at $300^{\circ} \mathrm{C}$. Tests were also made to check that under the catalytic conditions described and at low conversion, internal and external diffusion limitations could be neglected. Numerous tests of repeatability and reproducibility were performed to validate the conditions of reaction.

The activities of the catalysts expressed in $\mu \mathrm{mol} \cdot \mathrm{s}^{-1} \cdot \mathrm{g}_{\text {metal }}{ }^{-1}$ were compared at $60^{\circ} \mathrm{C}$. Since at this temperature, activity was very low, activity was calculated from the apparent activation energy measured from the Arrhenius plot In(activity) versus $1 / T$. TOF expressed per surface gold atom was estimated as follows : TOF $=$ activity $_{60^{\circ} \mathrm{C}} \cdot \mathrm{D} / \mathrm{M}_{\mathrm{Au}}$. The dispersion $\mathrm{D}$ was deduced from the volumic average gold particle $\left(\mathrm{d}_{\mathrm{av}}\right.$.) measured by TEM and plots of the dispersion versus average platinum particle size (17).

\section{Results}

\section{A. Catalyst characterisation}

The gold loadings and average gold particle size of the samples reduced at $300^{\circ} \mathrm{C}$ are reported in Tables 1-4. The results show that all the samples contain the expected Au loading (1 wt \%), and that the chlorine content in the DPU samples is always below the detection limit of measurement. As expected the samples prepared by impregnation in excess of solution (IE) and anionic adsorption (AA) contain a higher amount of chlorine (13).

A former XAFS study showed that gold on ceria, alumina, titania prepared by deposition-precipitation with urea was fully reduced into metallic gold after reduction under $\mathrm{H}_{2}$ at $300^{\circ} \mathrm{C}$ (18), with no detectable traces of Au'll' or Au'. The TPR profiles reported in Figure 1 confirm that gold is reduced below $300^{\circ} \mathrm{C}$. They also show that the reducibility of gold depends on the nature of the support, in agreement with the same former study (18), and also on the preparation method. The temperatures corresponding to the maximum of the reduction peaks was around $110^{\circ} \mathrm{C}$ for $\mathrm{Au} / \mathrm{TiO}_{2}, 130^{\circ} \mathrm{C}$ for $\mathrm{Au} /$ $\mathrm{CeO}_{2}, 160^{\circ} \mathrm{C}$ for $\mathrm{Au} / \mathrm{ZrO}_{2}$ and $170^{\circ} \mathrm{C}$ for $\mathrm{Au} / \mathrm{Al}_{2} \mathrm{O}_{3}$ (DPU 
Table 1

Gold catalysts prepared by DPU on different supports: gold and chlorine contents, gold particle size after reduction at $300^{\circ} \mathrm{C}$ in $\mathrm{H}_{2}$, activity and TOF at $60^{\circ} \mathrm{C}$

\begin{tabular}{|c|c|c|c|c|c|c|}
\hline \multirow[b]{2}{*}{ Catalysts } & \multicolumn{2}{|c|}{ Loading (wt \%) } & \multicolumn{2}{|c|}{ Average gold particle size (nm) } & \multirow{2}{*}{$\begin{array}{l}\text { Activity at } 60^{\circ} \mathrm{C} \\
\left(\mu \mathrm{mol} . \mathrm{s}^{-1} \cdot \mathrm{g}_{\mathrm{Au}}^{-1}\right)\end{array}$} & \multirow{2}{*}{$\begin{array}{c}\text { TOF at } 60^{\circ} \mathrm{C} \\
\left(10^{-3} \mathrm{~s}^{-1}\right)\end{array}$} \\
\hline & $\mathrm{Au}$ & $\mathrm{Cl}$ & $\begin{array}{l}\text { Arithmetic } \\
\text { mean }\end{array}$ & $\begin{array}{l}\text { Volumic } \\
\text { mean }\end{array}$ & & \\
\hline $\mathrm{Au} / \mathrm{TiO}_{2} \mathrm{DPU}$ & 1.1 & $<0.02$ & $1.7(0.60)^{*}$ & 2.2 & 5.6 & 2.3 \\
\hline $\mathrm{Au} / \mathrm{Al}_{2} \mathrm{O}_{3} \mathrm{DPU}$ & 0.9 & $<0.02$ & $2.2(0.85)$ & 2.8 & 4.9 & 2.5 \\
\hline $\mathrm{Au} / \mathrm{ZrO}_{2} \mathrm{DPU}$ & 0.9 & $<0.02$ & $2.1(0.70)$ & 2.6 & 3.3 & 1.6 \\
\hline $\mathrm{Au} / \mathrm{CeO}_{2} \mathrm{DPU}$ & 1.0 & $<0.02$ & - & - & 4.5 & - \\
\hline
\end{tabular}

* standard deviation

Table 2

$\mathrm{Au} / \mathrm{TiO} \mathrm{O}_{2}$ and $\mathrm{Au} / \mathrm{Al}_{2} \mathrm{O}_{3}$ prepared by DPU at various gold loadings: gold and chlorine contents, gold particle size after reduction at $300^{\circ} \mathrm{C}$ in $\mathrm{H}_{2}$, activity and TOF at $60^{\circ} \mathrm{C}$

\begin{tabular}{|c|c|c|c|c|c|c|}
\hline \multirow[b]{2}{*}{ Catalysts } & \multicolumn{2}{|c|}{ Loading (wt \%) } & \multicolumn{2}{|c|}{ Average gold particle size (nm) } & \multirow{2}{*}{$\begin{array}{l}\text { Activity at } 60^{\circ} \mathrm{C} \\
\left(\mu \mathrm{mol} \cdot \mathrm{s}^{-1} \cdot \mathrm{g}_{\mathrm{Au}}^{-1}\right)\end{array}$} & \multirow{2}{*}{$\begin{array}{c}\text { TOF at } 60^{\circ} \mathrm{C} \\
\left(10^{-3} \mathrm{~s}^{-1}\right)\end{array}$} \\
\hline & $\mathrm{Au}$ & $\mathrm{Cl}$ & $\begin{array}{c}\text { Arithmetic } \\
\text { mean }\end{array}$ & $\begin{array}{l}\text { Volumic } \\
\text { mean }\end{array}$ & & \\
\hline $\mathrm{Au} / \mathrm{Al}_{2} \mathrm{O}_{3} \mathrm{DPU} 1 \mathrm{wt} \%$ & 0.9 & $<0.02$ & $2.2(0.85)^{*}$ & 2.8 & 4.9 & 2.5 \\
\hline $\mathrm{Au} / \mathrm{Al}_{2} \mathrm{O}_{3} \mathrm{DPU} 2 \mathrm{wt} \%$ & 1.7 & $<0.02$ & $2.2(0.74)$ & 2.7 & 3.6 & 1.6 \\
\hline $\mathrm{Au} / \mathrm{Al}_{2} \mathrm{O}_{3} \mathrm{DPU} 3 \mathrm{wt} \%$ & 3.1 & $<0.03$ & $2.2(0.81)$ & 2.9 & 3.5 & 1.8 \\
\hline $\mathrm{Au} / \mathrm{TiO}_{2}$ DPU 1wt \% & 1.1 & $<0.02$ & $1.7(0.60)$ & 2.2 & 5.6 & 2.3 \\
\hline $\mathrm{Au} / \mathrm{TiO}_{2}$ DPU $2 \mathrm{wt} \%$ & 2.1 & $<0.02$ & $2.2(0.81)$ & 2.9 & 5.4 & 2.2 \\
\hline
\end{tabular}

* standard deviation

Table 3

$\mathrm{Au} / \mathrm{TiO} \mathrm{O}_{2}$ and $\mathrm{Au} / \mathrm{Al}_{2} \mathrm{O}_{3}$ prepared by DPU: gold and chlorine contents, gold particle size after different thermal treatments, activity and TOF for hydrogenation at $60^{\circ} \mathrm{C}$

\begin{tabular}{|c|c|c|c|c|c|c|c|c|}
\hline \multirow[b]{2}{*}{ Catalysts } & \multicolumn{2}{|c|}{ Loading (wt \%) } & \multicolumn{2}{|c|}{ Activation } & \multicolumn{2}{|c|}{$\begin{array}{c}\text { Average gold } \\
\text { particle size }(\mathrm{nm})\end{array}$} & \multirow{2}{*}{$\begin{array}{c}\text { Activity at } 60^{\circ} \mathrm{C} \\
\left(\mu \mathrm{mol} . \mathrm{s}^{-1} \cdot \mathrm{g}_{\mathrm{Au}}^{-1}\right)\end{array}$} & \multirow{2}{*}{$\begin{array}{c}\text { TOF at } 60^{\circ} \mathrm{C} \\
\left(10^{-3} \mathrm{~s}^{-1}\right)\end{array}$} \\
\hline & $\mathrm{Au}$ & $\mathrm{Cl}$ & Gas & Temp ${ }^{\circ} \mathrm{C}$ & $\begin{array}{l}\text { Arithmetic } \\
\text { mean }\end{array}$ & $\begin{array}{l}\text { Volumic } \\
\text { mean }\end{array}$ & & \\
\hline $\mathrm{Au} / \mathrm{TiO}_{2} \mathrm{DPU}$ & 1.1 & $<0.02$ & Air & 300 & $2.9(0.85)^{*}$ & 3.4 & 4.5 & 2.5 \\
\hline $\mathrm{Au} / \mathrm{TiO}_{2} \mathrm{DPU}$ & 1.1 & $<0.02$ & Air & 400 & $3.2(1.02)$ & 3.9 & 4.2 & 2.7 \\
\hline $\mathrm{Au} / \mathrm{TiO}_{2} \mathrm{DPU}$ & 1.1 & $<0.02$ & Air & 500 & $3.9(1.04)$ & 4.4 & 3.9 & 2.6 \\
\hline $\mathrm{Au} / \mathrm{TiO}_{2} \mathrm{DPU}$ & 1.1 & $<0.02$ & $\mathrm{H}_{2}$ & 300 & $1.7(0.60)$ & 2.2 & 5.6 & 2.3 \\
\hline $\mathrm{Au} / \mathrm{TiO}_{2} \mathrm{DPU}$ & 1.1 & $<0.02$ & $\mathrm{H}_{2}$ & 500 & $2.1(0.65)$ & 2.5 & 5.4 & 2.5 \\
\hline $\mathrm{Au} / \mathrm{TiO}_{2} \mathrm{DPU}$ & 1.1 & $<0.02$ & $\mathrm{H}_{2}$ & 300 & $3.1(1.35)$ & 4.3 & 4.3 & 2.9 \\
\hline $\mathrm{Au} / \mathrm{Al}_{2} \mathrm{O}_{3} \mathrm{DPU}$ batch 1 & 0.9 & $<0.02$ & $\mathrm{H}_{2}$ & 300 & $1.9(0.42)$ & 2.1 & 5.1 & 2.0 \\
\hline $\mathrm{Au} / \mathrm{Al}_{2} \mathrm{O}_{3}$ DPU batch2 & 0.8 & $<0.02$ & $\mathrm{H}_{2}$ & 300 & $2.1(0.66)$ & 2.4 & 5.2 & 2.3 \\
\hline $\mathrm{Au} / \mathrm{Al}_{2} \mathrm{O}_{3} \mathrm{DPU}$ batch 3 & 0.9 & $<0.02$ & $\mathrm{H}_{2}$ & 300 & $2.2(0.85)$ & 2.8 & 4.9 & 2.5 \\
\hline $\mathrm{Au} / \mathrm{Al}_{2} \mathrm{O}_{3}$ DPU batch 4 & 0.9 & $<0.02$ & $\mathrm{H}_{2}$ & 300 & $2.2(0.85)$ & 2.8 & 4.7 & 2.4 \\
\hline
\end{tabular}

* standard deviation

catalysts). It is worth noting that the hydrogen consumption for the $\mathrm{Au} / \mathrm{CeO}_{2}$ sample is about ten times as high as that for the other samples, and corresponds to the simultaneous reduction of $\mathrm{Au}^{\mathrm{III}}$ and ceria surface support, as already observed in several other studies, e.g. (19). The hydrogen consumption monitored for the $\mathrm{Au} / \mathrm{Al}_{2} \mathrm{O}_{3}$ catalysts prepared by $A A$ and IE is observed at higher temperature, i.e. 190 and $200^{\circ} \mathrm{C}$, respectively.

The DPU samples contain very small gold particles after reduction under hydrogen at $300^{\circ} \mathrm{C}$ with almost the same size $(\sim 2 \mathrm{~nm})$ whatever the support (Table 1). The gold particle size does not depend on the gold loading within the range of loading investigated (Table 2 ). It can be recalled that very small gold particles were also obtained on $8 \mathrm{wt} \%$ 
$\mathrm{Au} / \mathrm{TiO}_{2}$ and $\mathrm{Au} / \mathrm{Al}_{2} \mathrm{O}_{3}$ prepared by different methods: gold and chlorine contents, gold particle size after different thermal treatments, activity and TOF at $60^{\circ} \mathrm{C}$ (n.d. : not determined)

\begin{tabular}{|c|c|c|c|c|c|c|c|c|}
\hline \multirow[b]{2}{*}{ Catalysts } & \multicolumn{2}{|c|}{ Loading (wt \%) } & \multicolumn{2}{|c|}{ Activation } & \multicolumn{2}{|c|}{$\begin{array}{c}\text { Average gold } \\
\text { particle size }(\mathrm{nm})\end{array}$} & \multirow{2}{*}{$\begin{array}{c}\text { Activity at } 60^{\circ} \mathrm{C} \\
\left(\mu \mathrm{mol} \cdot \mathrm{s}^{-1} \cdot \mathrm{g}_{\mathrm{Au}}^{-1}\right)\end{array}$} & \multirow{2}{*}{$\begin{array}{c}\text { TOF at } 60^{\circ} \mathrm{C} \\
\left(10^{-3} \mathrm{~s}^{-1}\right)\end{array}$} \\
\hline & $\mathrm{Au}$ & $\mathrm{Cl}$ & Gas & Temp ${ }^{\circ} \mathrm{C}$ & $\begin{array}{c}\text { Arithmetic } \\
\text { mean }\end{array}$ & $\begin{array}{l}\text { Volumic } \\
\text { mean }\end{array}$ & & \\
\hline $\mathrm{Au} / \mathrm{Al}_{2} \mathrm{O}_{3}$ DPU unwashed & d 0.9 & n.d. & $\mathrm{H}_{2}$ & 300 & $3.4(1.14)^{*}$ & 4.1 & 2.6 & 1.7 \\
\hline $\mathrm{Au} / \mathrm{TiO}_{2} \mathrm{IE}$ & 1.1 & 0.88 & $\mathrm{H}_{2}$ & 300 & $2.7(0.98)$ & 3.4 & 2.4 & 1.4 \\
\hline $\mathrm{Au} / \mathrm{Al}_{2} \mathrm{O}_{3} \mathrm{IE}$ & 0.8 & 0.98 & $\mathrm{H}_{2}$ & 300 & $3.1(1.38)$ & 4.5 & 0.3 & 0.2 \\
\hline $\mathrm{Au} / \mathrm{Al}_{2} \mathrm{O}_{3} \mathrm{AA}$ & 0.9 & 0.81 & $\mathrm{H}_{2}$ & 300 & $3.2(1.15)$ & 4.0 & 0.6 & 0.4 \\
\hline
\end{tabular}

${ }^{*}$ standard deviation

$\mathrm{Au} / \mathrm{TiO}_{2}$ catalysts (11). When the DPU samples are reduced at higher temperature or are calcined in air, larger particle sizes are obtained (Table 3). This was also previously observed (20). As mentioned in Section Experimental, gold particle size on ceria cannot be measured by TEM (Table 1). However, no diffraction line of metal gold was observed by XRD. Moreover, according to a former XAFS study performed on DPU $\mathrm{Au} / \mathrm{CeO}_{2}$ samples of almost the same gold loading, the extent of the contraction of the Au-Au bond length and the low Au-Au coordination number indicated that the average gold particle size was less than $3 \mathrm{~nm}$ (21).

One can note that when the samples contain chlorides (unwashed DPU) and/or are prepared by another method than DPU (AA and IE, Table 4), the gold particles are larger for the same conditions of reduction. Rather small gold particles are nevertheless obtained under hydrogen, which is not the case when a calcination treatment is applied (13).

CO adsorption monitored by DRIFT spectroscopy was performed on two $\mathrm{Au} / \mathrm{Al}_{2} \mathrm{O}_{3}$ samples after in situ reduction in the IR cell under $\mathrm{H}_{2}$ up to $300^{\circ} \mathrm{C}$ : one sample prepared by DPU (gold particle size $\sim 2 \mathrm{~nm}$ ) and one by impregnation in excess of solution (IE) (gold particle size $\sim 3 \mathrm{~nm}$ ) (Figure 2). In the case of the DPU sample, CO adsorption at RT leads to a

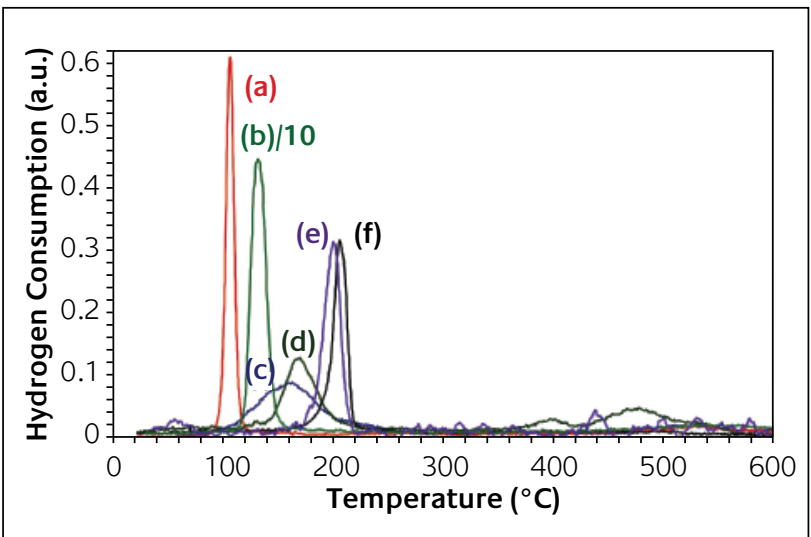

\section{Figure 1}

TPR profiles of as-prepared DPU samples: (a) $\mathrm{Au} / \mathrm{TiO}_{2}$, (b) $\mathrm{Au} / \mathrm{CeO}_{2}$ (intensity divided by 10) (c) $\mathrm{Au} / \mathrm{ZrO}_{2}$, (d) $\mathrm{Au} / \mathrm{Al}_{2} \mathrm{O}_{3}$ and of as-prepared $\mathrm{Au} / \mathrm{Al}_{2} \mathrm{O}_{3}$ prepared by $(e)$ anionic adsorption $(A A)$ and $(f)$ impregnation with excess of solution (IE) single, narrow and symmetric band at $2104 \mathrm{~cm}^{-1}$, which typically corresponds to $\mathrm{CO}$ adsorbed on low coordination $\mathrm{Au}^{0}$ sites of metallic gold surfaces (22-25). The IE catalyst shows a low intense and broad $\mathrm{CO}$ band at much lower energy, $2063 \mathrm{~cm}^{-1}$. It may be attributed to CO adsorbed on negatively charged gold clusters due to charge transfer (25). The negatively charged gold species may arise from the presence of chlorides either on the alumina support close to the particle, or maybe even on the gold particle itself, as reported in recent papers $(26,27)$. A second band, less intense at $2127 \mathrm{~cm}^{-1}$ may be attributed to $\mathrm{CO}$ adsorbed on positively charged $\mathrm{Au}^{\delta+}$ species of electro-deficient gold particles, possibly made electropositive by the proximity of oxygen $(22,24,28-30)$.

\section{B. Catalytic results}

Figure 3 indicates the conversion of butadiene and propene and the formation of the products as a function of temperature over a DPU Au/ $/ \mathrm{Al}_{2} \mathrm{O}_{3}$ catalyst. Figure 3 shows that at $\sim 170^{\circ} \mathrm{C}$, the whole butadiene has been converted into butenes without formation of butane (less than $5 \mathrm{ppm}$ ) and without significant hydrogenation of propene to propane $(\sim 100$ ppm). Even at $300^{\circ} \mathrm{C}$, the amounts of butane and propane formed do not exceed $\sim 15$ ppm and $\sim 1500$ ppm, respectively,

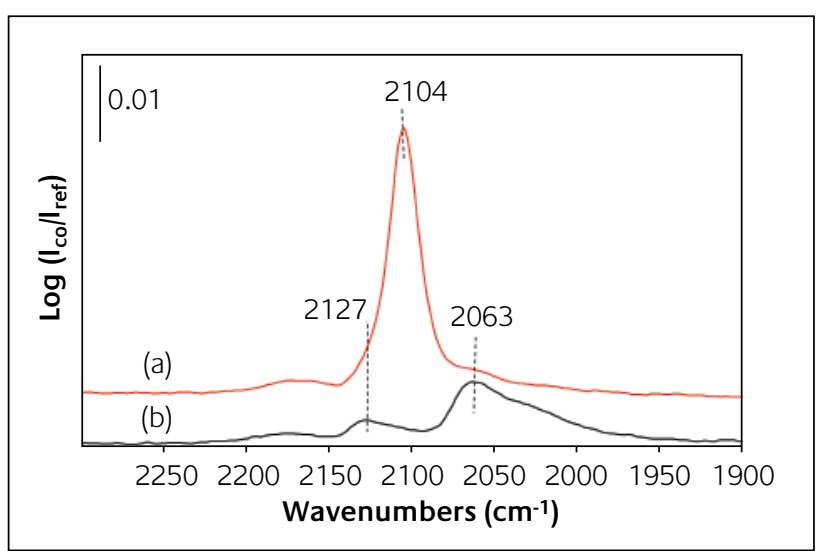

Figure 2

DRIFT spectra under $1 \% \mathrm{CO} / \mathrm{He}$ at $\mathrm{RT}$ on $\mathrm{Au} / \mathrm{Al}_{2} \mathrm{O}_{3}$ prepared by (a) deposition-precipitation with urea (DPU) and (b) impregnation with excess of solution (IE) (activation in $\mathrm{H}_{2}$ at $300^{\circ} \mathrm{C}$ ) 


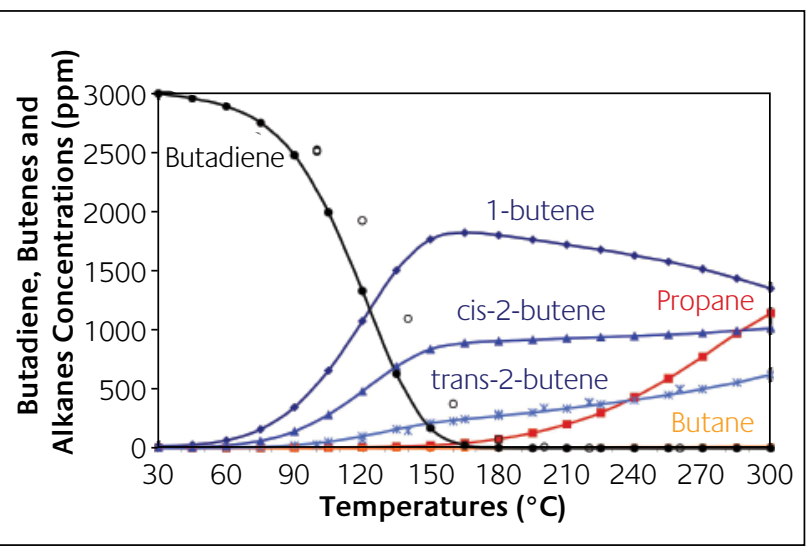

Figure 3

Typical reactivity of a gold catalyst (DPU Au/Al $\mathrm{O}_{3}$, activation in $\mathrm{H}_{2}$ at $300^{\circ} \mathrm{C}, 0.9 \mathrm{wt} \% \mathrm{Au}$ and $<200 \mathrm{ppm} \mathrm{Cl}$ in selective hydrogenation of butadiene in the presence of an excess of propene: Evolution of the concentrations of butadiene and products as a function of the reaction temperature. The open symbols correspond to the concentrations of butadiene at decreasing temperature

which is very low if one considers that there is $30 \%$ of propene in the gas flow. One can also note that at $\sim 170^{\circ} \mathrm{C}$ and at $300^{\circ} \mathrm{C}$, the amount of butane produced is about 100 times as low as that of propane, i.e., the propane/butane ratio is equal to the propene/butenes ratio. This suggests that the reactivity of propene is the same as butenes, and validates the choice of replacing butene by propene (see Introduction). The same type of catalytic behaviour was obtained with all the gold catalysts tested in this work.

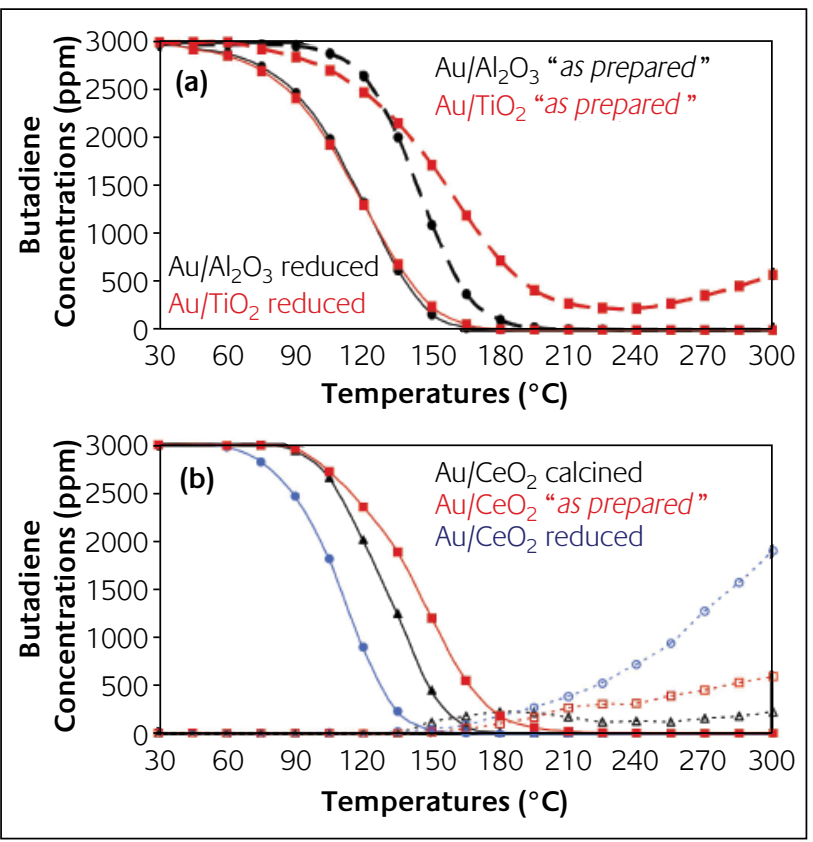

\section{Figure 5}

Evolution of the butadiene (full symbols) and alkanes (open symbols) concentrations as a function of the reaction temperature in selective hydrogenation of butadiene in the presence of an excess of propene for

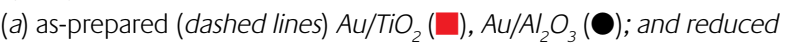

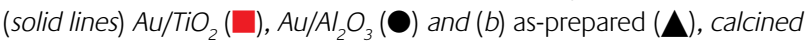
(口) and reduced $\mathrm{Au} / \mathrm{CeO}_{2}(\mathbf{O})\left(\mathrm{DPU}\right.$ samples, 1 wt \% Au, reduction in $\mathrm{H}_{2}$ at $300^{\circ} \mathrm{C}$ or calcination in air at $500^{\circ} \mathrm{C}$ )

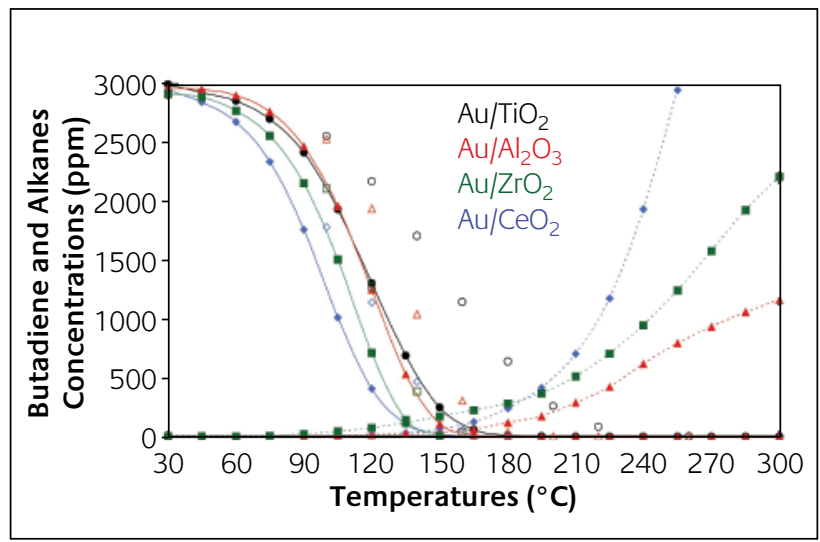

Figure 4

Evolution of the butadiene (solid lines) and alkanes (dashed lines) concentrations as a function of the reaction temperature in selective hydrogenation of butadiene in the presence of an excess of propene for DPU gold catalysts supported on different supports: titania $(\mathbf{O})$, alumina $(\mathbf{\Delta})$, zirconia $(\square)$ and ceria $(\diamond)$ (see Table 1). The open symbols correspond to the concentrations of butadiene at decreasing temperature

Figure 3 also shows that 1-butene is the main product, and that the percentages in the different butenes vary as follows: 1-butene > cis-2-butene > trans-2-butene. Their proportions change with temperature with a slight decrease in 1-butene and an increase in trans-2-butene, more important than that of cis-2-butene, indicating isomerisation $(4,6,31)$. Almost the same evolution of the percentages in the different butenes as a function of the reaction temperature was observed with all the gold catalysts presented in this study, therefore for the sake of clarity, they are not reported in the following figures.

The catalytic properties of gold supported on different oxides, $\mathrm{TiO}_{2}, \mathrm{Al}_{2} \mathrm{O}_{3}, \mathrm{ZrO}_{2}$ and $\mathrm{CeO}_{2}$, were compared. These samples were prepared by the same DPU method, they contain 1 wt \% Au and no detectable chlorides, and their gold particle size is almost the same, about $2 \mathrm{~nm}$, after the same activation step under $\mathrm{H}_{2}$ at $300^{\circ} \mathrm{C}$ (Table 1). Figure 4 shows that the curves of conversion of butadiene versus temperature are almost superimposed, except maybe for Au/ $\mathrm{CeO}_{2}$, which seems to be slightly more active, but its activity at $60^{\circ} \mathrm{C}$ is roughly the same as that of the other samples (Table 1). The selectivities to butenes and alkanes are independent on the support, and are the same as those shown in Figure 3. Table 1 shows that the activities and TOF are rather similar for all the samples $\left(\sim 5 \mu \mathrm{mol} . \mathrm{s}^{-1} \cdot \mathrm{g}_{\mathrm{Au}}{ }^{-1}\right.$ and $\sim 2$ $10^{-3} \mathrm{~s}^{-1}$, respectively).

Figure 4 also shows differences in butadiene conversions between those measured at increasing temperature (full symbols) and those measured at decreasing temperature (isolated open symbols), indicating catalyst deactivation. These differences vary from one catalyst to another: gold on titania shows the highest deactivation, while gold on ceria shows the lowest. Hence, the nature of the support seems to play a role in catalyst deactivation. This will be discussed in a future paper (32).

The influence of the gold oxidation state was also 
investigated. The activity of as-preparedsamples, i.e. containing the Au ${ }^{\text {III }}$ species of the deposited precursor, was compared to catalysts activated under $\mathrm{H}_{2}$, i.e. containing metallic gold. Figure 5 shows that the three as-prepared $\mathrm{Au} / \mathrm{TiO}_{2}, \mathrm{Au} / \mathrm{CeO}_{2}$ and $\mathrm{Au} / \mathrm{Al}_{2} \mathrm{O}_{3}$ catalysts are less active than the catalysts activated under $\mathrm{H}_{2}$. Instead of showing an activity from $\sim 45^{\circ} \mathrm{C}$ as in the case of the reduced samples, they become active at higher temperature, 60,90 and $100^{\circ} \mathrm{C}$, respectively. These results, combined to the results of TPR, i.e. the temperatures at which gold starts reducing (Figure 1), and to the fact that the reactant flow is a reducing mixture (hydrogen and alkenes), are an indication that gold initially in the oxidation state III is not active, and that it becomes active when Au $\mathrm{u}^{\mathrm{III}}$ starts reducing into $\mathrm{Au}^{\mathrm{O}}$ under the reactant stream. The sample colours after reaction, i.e., deep violet for $\mathrm{Au} / \mathrm{TiO}_{2}$, dark-brown for $\mathrm{Au} / \mathrm{CeO}_{2}$, pinkpurple for $\mathrm{Au} / \mathrm{Al}_{2} \mathrm{O}_{3}$, are also an indication that gold reduces during reaction.

The requirement of the presence of $\mathrm{Au}^{0}$ for an active catalyst is confirmed with the experiments performed with $\mathrm{Au} / \mathrm{CeO}_{2}$ sample. It has been shown that in contrast to other supports such as alumina or titania, ceria stabilises gold in the oxidation state Au $\mathrm{u}^{\text {III }}$ after calcination up to $500^{\circ} \mathrm{C}$ (18). Figure 5b shows that $\mathrm{Au} / \mathrm{CeO}_{2}$ sample calcined at $500^{\circ} \mathrm{C}$ is even less

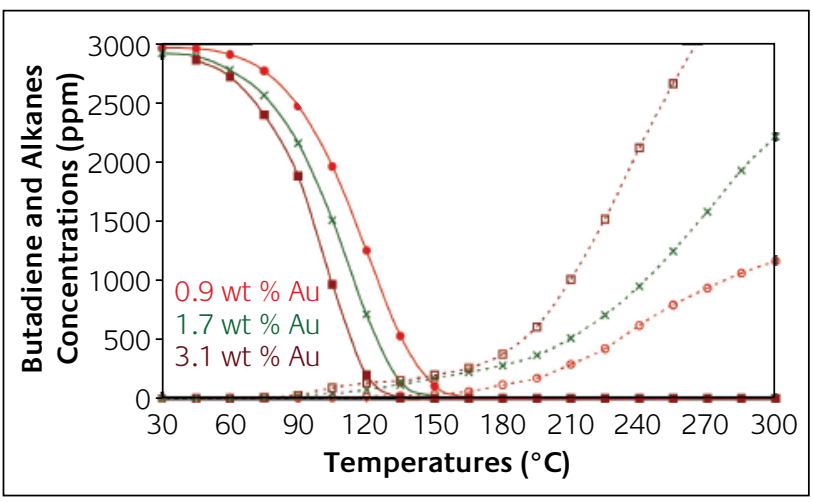

\section{Figure 6}

Evolution of the butadiene (full symbols) and alkanes (open symbols) concentrations as a function of the reaction temperature in selective hydrogenation of butadiene in the presence of an excess of propene for $D P \cup A u / A_{2} \mathrm{O}_{3}$ with different gold loadings (see Table 2)

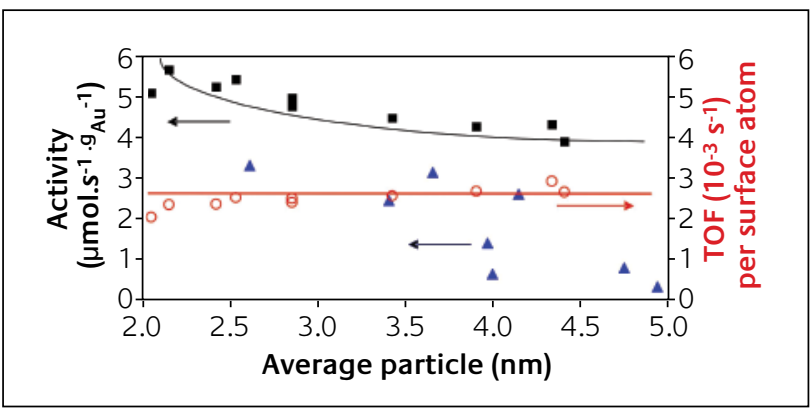

Figure 7

Evolution of the activity $(\mathbf{\square})$ and TOF $(\bigcirc)$ of DPU gold catalysts (several batches and different activations, see Table 3) in selective hydrogenation of butadiene in the presence of an excess of propene at $60^{\circ} \mathrm{C}$ as a function of the average gold particle size; activity of gold catalysts prepared by different methods and containing different levels of chlorine (A) as a function of the average gold particle size (see Table 4) active than the as-prepared sample.

Three $\mathrm{Au} / \mathrm{Al}_{2} \mathrm{O}_{3}$ catalysts prepared by the same DPU method, and containing different gold loadings, 1, 2 and 3 wt \%, but the same gold particle size (Table 2) were compared. Figure 6 shows that the conversion increases with the gold loading, and that the amount of alkanes (butane and propane) formed is also proportional to the gold loading. The activity at $60^{\circ} \mathrm{C}$ and the TOF are however nearly constant, and do not depend on the gold loading (Table 2). The same type of results was obtained with $\mathrm{Au} / \mathrm{TiO}_{2}$ catalysts (Table 2). The selectivities to butenes are not affected by changes in gold loading.

As shown in former papers $(15,20)$, it is possible to vary the gold particle size in the samples prepared by DPU by modifying the conditions of activation. A set of samples with different gold particle sizes was obtained with DPU samples submitted to different activation treatments, and also arising from different batches, or supported on different oxides.

Figure 7 shows that the activity at $60^{\circ} \mathrm{C}$ slightly decreases from 5 to $4 \mu \mathrm{mol} . \mathrm{s}^{-1} \cdot \mathrm{g}_{\mathrm{Au}}{ }^{-1}$ as the gold particle size increases from 2 to $5 \mathrm{~nm}$, while the TOF tends to slightly increase from 2.0 to $2.710^{-3} \mathrm{~s}^{-1}$.

Figure 7 also shows that the preparation method has a strong influence on the activity since the samples prepared by impregnation in excess of solution (IE) and anionic adsorption (AA) provide less active catalysts than those prepared by deposition-precipitation with urea for the same gold particle sizes and size distribution (Table 4). This is also the case for the unwashed DPU sample, which contains chlorides as do the IE and AA samples. The selectivity is also slightly affected since although 1-butene remains the main product, there is more isomerisation in trans-2-butene.

The influence of propene concentration (30, 20 and 0\%) on the hydrogenation of butadiene $(0.3 \%)$ was investigated over a DPU Au/Al $\mathrm{O}_{3}$ catalyst ( $1 \mathrm{wt} \%$ ). Figure $8 \mathrm{a}$ shows that the butadiene conversion slightly increases as propene concentration decreases. For instance, the activities at $60^{\circ} \mathrm{C}$ are 4.0, 4.9 and $5.3 \mu \mathrm{mol} . \mathrm{s}^{-1} \cdot \mathrm{g}_{\mathrm{Au}}{ }^{-1}$, respectively for 30,20 and $0 \%$ propene. The change is not drastic, and the influence of propene is rather weak if one remembers that $30 \%$ propene corresponds to a concentration 100 times as high as that of butadiene.

The influence of butadiene concentration ( 0.3 and $0 \%$ ) on the hydrogenation of propene $(30 \%)$ was also investigated over a DPU Au/Al $\mathrm{O}_{3}$ catalyst ( $1 \mathrm{wt} \%$ ). Figure $8 \mathrm{~b}$ shows that propene conversion is not affected by the presence or the absence of butadiene.

\section{Discussion}

\section{A. Activity}

Our results confirm that gold catalysts are active in reactions of hydrogenation, but much less than palladium. The gold activity was around $5 \mu \mathrm{mol} . \mathrm{s}^{-1} \cdot \mathrm{g}_{\mathrm{Au}}^{-1}$ at $60^{\circ} \mathrm{C}$ (Tables 1-3), whereas for example, that of palladium in hydrogenation of acetylene is about $100 \mu \mathrm{mol} . \mathrm{s}^{-1} \cdot \mathrm{g}_{\mathrm{Pd}}{ }^{-1}$ at $30^{\circ} \mathrm{C}$ or that of 
$\mathrm{Ag}-\mathrm{Pd} / \mathrm{Al}_{2} \mathrm{O}_{3}$ catalyst is $160 \mu \mathrm{mol} . \mathrm{s}^{-1} \cdot \mathrm{g}_{\mathrm{Pd}}^{-1}$ at $60^{\circ} \mathrm{C}$ (33). To increase the efficiency of gold catalysts to some extent, it is possible however to increase the gold loading since as reported in Figure 6 and Table 2, conversion is proportional to the amount of gold.

The poor catalytic activity of gold catalysts in hydrogenation compared to that of Pd or Pt catalysts is generally attributed to the fact that gold hardly dissociates molecular $\mathrm{H}_{2}$, as established experimentally and theoretically (34-36). However, several authors have observed the dissociative chemisorption of $\mathrm{H}_{2}\left(\mathrm{D}_{2}\right)$ on gold films. Okada et al. (37) who studied the adsorption and reaction of hydrogen (deuterium) on thin gold film grown on Ir (111), noticed that $\mathrm{H}_{2}\left(\mathrm{D}_{2}\right)$ can dissociatively adsorb on these Au films. They attributed this property to locally-relaxed surface features like defects. On thin gold film deposited on pyrex glass, Stobinski et al. (38) also found that $\mathrm{H}_{2}$ can dissociatively chemisorb, providing that the thin gold film was deposited at low temperature (78 $\mathrm{K}$ ) and was not sintered afterwards. They concluded that $\mathrm{H}_{2}$ chemisorption occurred only on surface atoms of low coordination number. Then, Zanella et al. (20) proposed that the activity of gold catalysts in selective hydrogenation of crotonaldehyde was determined by the dissociation step of molecular hydrogen, which was the rate-limiting step. More recently combined experiments of XAFS, $\mathrm{H}_{2}$ chemisorption and $\mathrm{H} / \mathrm{D}$ exchange have proven that hydrogen dissociatively adsorbs on the gold particles of $\mathrm{Au} / \mathrm{Al}_{2} \mathrm{O}_{3}$ catalysts prepared by impregnation and deposition-precipitation (39). The adsorption and dissociation of hydrogen were limited to the gold atoms on corner and edge positions. The authors also found that the hydrogen dissociation by gold was activated, and that both the activity in H/D exchange and the hydrogen uptake increased with temperature. They concluded that the low hydrogen coverage on gold nanoparticles implies that hydrogen adsorption/dissociation is the rate-limiting step in hydrogenation reaction.

The experiments reported in Figure 5 and commented on above provide a good indication that gold must be in the metallic state to be active, and that when gold is initially in cationic form, it reduces under the reactant stream before reaching $100^{\circ} \mathrm{C}$. The fact that gold must be metallic to be active was implicitly assumed by the authors who published papers on selective hydrogenation over gold catalysts, probably by comparison with other noble metal catalysts. However, two recent papers published by Xu et al. $(40,41)$ on 1,3-butadiene hydrogenation over $\mathrm{Au} / \mathrm{ZrO}_{2}$ catalysts seem to show that $\mathrm{Au}^{\text {III }}$ species would lead to higher activity than $\mathrm{Au}^{\circ}$. For instance, the authors found that for $\mathrm{Au} / \mathrm{ZrO}_{2}$ samples calcined at $200^{\circ} \mathrm{C}$, the conversion of a $0.08 \mathrm{wt} \%$ Au sample containing mainly Au"l species was higher than that of a 0.76 wt \% Au containing about $50 \%$ of $\mathrm{Au}^{\mathrm{II}}$ and $\mathrm{Au}^{\circ}$. Even though gold could reduce during the reaction performed at $120^{\circ} \mathrm{C}$ (the gold oxidation state was not characterised after reaction), this does not explain the difference of conversion between the two samples.

\section{B. Selectivity}

The advantage of the low hydrogenating activity of gold compared to palladium or platinum is that gold is very selective, as already mentioned in the Introduction. This is confirmed by the results reported in this paper. For instance Figure 3 shows that the gold catalysts are very selective for the hydrogenation of butadiene into butenes even in the presence of an excess of propene (100 times higher). Under our experimental conditions, it is possible to transform 100\% of the butadiene into butenes with only traces of butane formed ( $<5 \mathrm{ppm}$ ) at $\sim 170^{\circ} \mathrm{C}$, and only $100 \mathrm{ppm}$ of propene hydrogenated. Even at higher temperature (up to $300^{\circ} \mathrm{C}$ ), the conversion of propene and butenes into alkanes remains very low although it gradually increases with temperature ( 1500 ppm of propane at $300^{\circ} \mathrm{C}$, i.e. $0.5 \%$ conversion, and $\sim 15$ ppm of butane).

The selectivities obtained with our gold catalysts are much higher than those obtained with palladium catalysts. Even with bimetallic Pd catalysts, which are supposed to be much more selective than monometallic Pd catalysts, selectivities are not as good as for gold catalysts. For instance, Zhu et al. (33) reported that the conversion of ethylene into ethane over a bimetallic Pd-Ag catalyst was already equal to $0.3 \%$ at the lowest temperature for which 100\% conversion of acetylene was just reached. A few degrees above this temperature, selectivity drastically dropped.

The slightly higher activity of gold catalysts in hydrogenation of butadiene when propene was removed from the reaction mixture (Figure 8 ) indicates a competition of adsorption between propene and butadiene and/or hydrogen on the gold surface sites. It seems that adsorbed propene limits the access of the gold sites to the other reactants. However, propene adsorption is probably weak, otherwise butadiene hydrogenation would be inhibited. Jia et al. (7) compared the amount of alkenes and alkynes adsorbed at $0^{\circ} \mathrm{C}$ on an $\mathrm{Au} / \mathrm{Al}_{2} \mathrm{O}_{3}$ catalyst, and found 0.92 molecule of acetylene adsorbed per surface atom of gold and only 0.05 molecule of ethylene, i.e. a ratio of about 20 between the two molecules. It can be anticipated that the ratio is of the same order for butadiene and propene.

Again, palladium behaves much differently. Over palladium catalysts, the rate of hydrogenation of alkenes is higher than that of alkynes or alkadienes. The selective hydrogenation of acetylene carried out by Jia et al. (7) and of hydrogenation of 1,3-butadiene performed by Silvestre-Albero et al. (10), both over $\mathrm{Au} / \mathrm{Al}_{2} \mathrm{O}_{3}$, show the same features. The stronger adsorption on palladium of acetylene/butadiene than ethylene/ butenes inhibits the adsorption of alkenes, and therefore their hydrogenation, which results in a high selectivity to partially hydrogenated products. In contrast, in the absence of acetylene/butadiene, ethylene/butenes are readily hydrogenated. As a consequence, as long as alkenes and alkynes/alkadienes are both present on palladium surfaces, the later are preferentially hydrogenated into alkenes, but when almost all the alkynes/alkadienes are hydrogenated, alkenes can adsorb and react with a much higher rate than the 


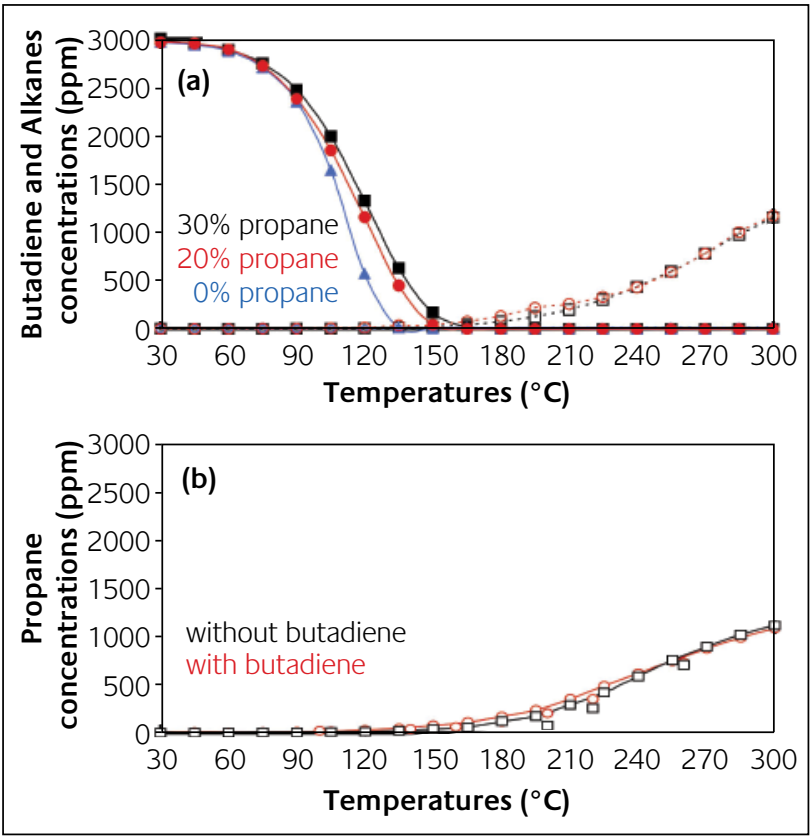

\section{Figure 8}

Evolution of the butadiene (full symbols) and alkanes (open symbols) concentrations as a function of the reaction temperature for DPU $\mathrm{Au} / \mathrm{Al}_{2} \mathrm{O}_{3}$ catalysts in (a) butadiene hydrogenation as a function of propene concentration: $0(\mathbf{\Lambda}), 20(\mathbf{O})$ and $30 \%(\square \square)$; (b) propene hydrogenation in the presence $(\bigcirc)$ or absence of butadiene $(\square)$ (activation in $\mathrm{H}_{2}$ at $300^{\circ} \mathrm{C}, 0.9$ wt \% Au and <200 ppm Cl)

remaining alkynes/alkadienes, leading to a collapse of the selectivity. The selectivity of palladium catalysts therefore results from a competition of adsorption between the two types of molecules.

If gold catalysts behaved on the same principle, one should observe the formation of high amounts of alkanes when butadiene is absent from the reaction mixture. However, figure $8 b$ shows no difference in reactivity of propene whether butadiene is present or absent. Vice versa, the absence of propene in the reaction mixture does not drastically influence the hydrogenation of butadiene, or selectivities (Figure 8a). This clearly indicates that the reason for the high selectivity of gold is totally different from that of palladium. Thus, it can be concluded that the two reactions of hydrogenation of butadiene and of alkenes are barely related one to the other: they take place in two different ranges of temperatures (low temperature range for butadiene and higher temperature range for propene), and the presence of one type of molecule only slightly influences the reactivity of the other (Figure 8).

\section{Butene distribution}

The same distribution of butenes, i.e., 1-butene > cis-2butene $>$ trans-2-butene (Figure 3) was obtained by Okumura et al. (6) over $\mathrm{Au} / \mathrm{Al}_{2} \mathrm{O}_{3}$ during butadiene hydrogenation (2\% in $\mathrm{H}_{2}$ ). The high proportion of 1-butene at low conversion is in agreement with the results obtained by Moyes et al. (42) on gold films and these authors correlated this high selectivity in 1-butene to the high Pauling electronegativity of metallic gold. Figure 9, which reports the evolution of the percentages versus reaction temperature, shows that the product distribution varies over the whole temperature range of reaction, and that as temperature increases, part of 1-butene gradually transforms mainly into trans-2-butene, which is thermodynamically the most stable butene. The fact that this phenomenon occurs at any temperature, and that the amount of trans-2-butene gradually increases as temperature increases is an indication that the change in product distribution results from isomerisation of 1-butene to 2butenes. This is confirmed by the fact that Inami et al. (31) who specifically studied the reaction of isomerisation over unsupported gold micro-spheres $(44-53 \mu \mathrm{m})$, observed the isomerisation of 1-butene to 2-butenes under hydrogen at $300^{\circ} \mathrm{C}$. Okumura et al. (6) also reported experiments indicating that 1-butene isomerises to 2-butenes in $\mathrm{H}_{2}$ stream. This phenomenon of isomerisation not only indicates that alkene adsorbs on gold particles (specific adsorption measurements performed by Jia et al. (7) also proved it), but also shows that gold is able to break $\mathrm{C}-\mathrm{H}$ bonds.

Again the behaviour of gold catalysts is different from that of palladium. With palladium, 1-butene remains the main product as long as butadiene conversion has not reached $100 \%$. Then, when all the butadiene has reacted,

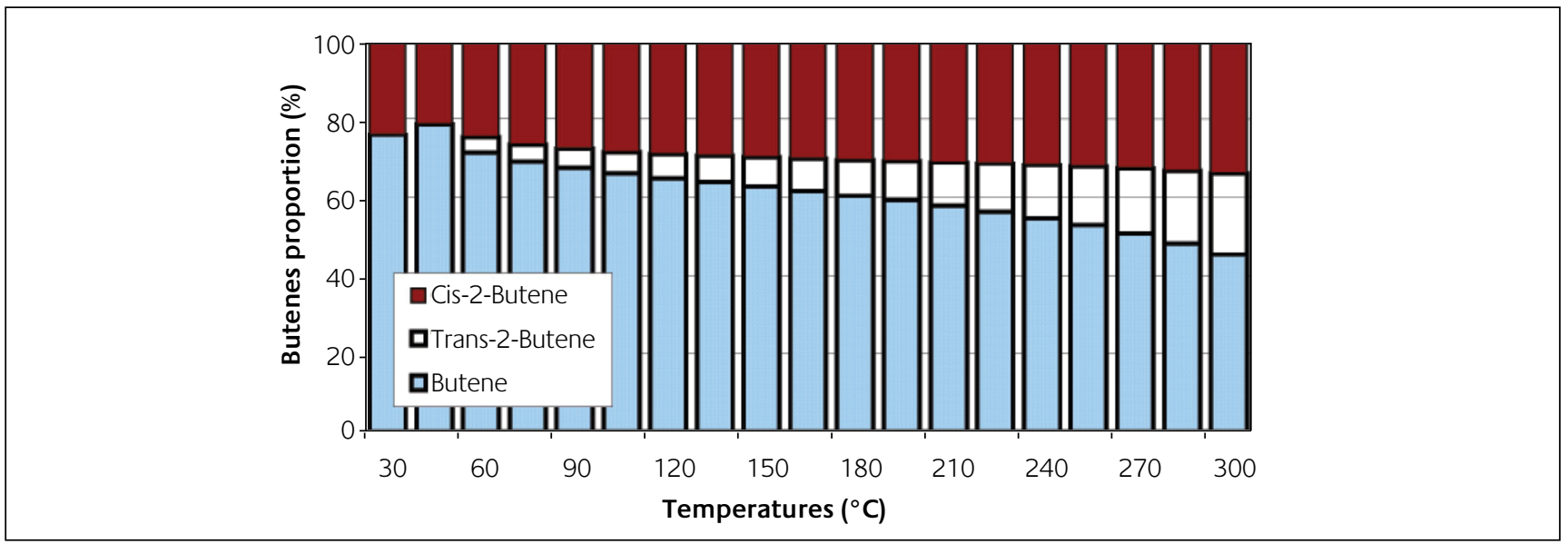

Figure 9

Proportion in the different butenes produced in selective hydrogenation of butadiene in the presence of an excess of propene (same experiment as in Figure 1) 
isomerisation suddenly occurs, and 1-butene transforms to trans-2-butene, which becomes the main butene, and to cis-2-butene (10). With gold, 1-butene is always the main product in spite of slight isomerisation. Note that 1-butene is the most desirable product for application (see Introduction).

\section{Relation between the nature of the catalyst and the catalytic activity}

\section{Influence of the oxide support}

Our results do not indicate significant influence of the nature of the oxide support on the catalytic properties of gold (except on deactivation, which will be discussed in a future paper (32)) (Figure 4, Table 1). This result is not consistent with Buchanan and Webb's (5) who showed that gold on $\gamma$ alumina and boehmite was active whereas gold on $\alpha$ alumina and silica was inactive in hydrogenation of butadiene at $200^{\circ} \mathrm{C}$. Note that these samples were prepared by impregnation ( $1 \mathrm{wt} \%$ of $\mathrm{Au}$ ), and exhibited a broad distribution of particle sizes up to $80 \mathrm{~nm}$ with the largest population of size in the $0-10 \mathrm{~nm}$ range. Our results are however in agreement with those of a more recent study performed by Haruta's team (6). They did not observe a significant difference between gold catalysts supported on alumina, silica or titania in selective hydrogenation of butadiene.

The absence of oxide support effect on the catalytic activity and selectivity is a good indication that the hydrogenation of alkenes only occurs on the gold particles, and that the support does not directly participate to the reaction. This is in contrast with reactions of oxidation, such as CO oxidation. In reactions of oxidation, oxygen activation possibly occurs on the oxide supports when they are reducible or at the gold-support interface $(3,43-46)$. In contrast, in the case of hydrogenation, as mentioned above, low coordination sites on gold particles can dissociate $\mathrm{H}_{2}$. Therefore, a direct involvement of the support is not required, although this hypothesis was once proposed by Buchanan and Webb (5).

\section{Influence of the gold particle size}

The moderate evolution of activity and TOF as temperature increases (Figure 7) demonstrates that the gold particles size has not a drastic influence on the catalytic properties. Indeed, the TOF increases by a factor 1.3 when the particle size varies from 5 to $2 \mathrm{~nm}$. This variation is small compared with that obtained in the reaction of $\mathrm{CO}$ oxidation, for which gold particles larger $5 \mathrm{~nm}$ are almost inactive, and the TOF increases by a factor of $\sim 18$ (47) and activity per $\mathrm{g}$ of gold by a factor of $\sim 25$ (48) for gold particles between 5 and $2 \mathrm{~nm}$. The same limited variation of TOF in hydrogenation of butadiene was observed by Okumura et al. (6) for the same range of gold particle size. The authors concluded that the hydrogenation of butadiene was not structure-sensitive to the particle size. It may be noted that the TOFs determined by these authors were smaller than ours, $2.10^{-3} \mathrm{~s}^{-1}$ instead of $80.10^{-3} \mathrm{~s}^{-1}$ at $150^{\circ} \mathrm{C}$ for gold particle size around $2 \mathrm{~nm}$.

One can note again the drastic difference with $\mathrm{Pd} / \mathrm{Al}_{2} \mathrm{O}_{3}$ catalysts, for which the TOF also expressed per surface atom linearly increased by a factor of 10 for Pd particle sizes increasing from 2 to $8 \mathrm{~nm}$ (10).

Influence of the preparation method and the presence of chlorides

The lower activity of the catalysts containing chlorine compared to those with the same gold particle size but free of chlorine (Figure 7, Table 4) indicates that chlorides inhibit the reaction, and that it is important to control their amount deposited on the catalyst during preparation. The issue of the presence of chlorine, which poison the gold catalysts, and must be eliminated, was also reported by Okumura et al. (6). They found that $\mathrm{Au} / \mathrm{Al}_{2} \mathrm{O}_{3}$ catalyst prepared by impregnation became more active in butadiene hydrogenation if after calcination performed to reduce gold, the sample was washed in hot water, which removed chlorine.

Several reasons for the inhibition of the reaction when chlorine is present in catalysts can be anticipated. The DRIFTS$\mathrm{CO}$ experiments performed on $\mathrm{Au} / \mathrm{Al}_{2} \mathrm{O}_{3}$ samples containing chlorine or free of chlorine, reveal differences in the frequencies of $\mathrm{CO}$ vibration (Figure 2). The main $\mathrm{CO}$ band at low wavenumber $\left(2063 \mathrm{~cm}^{-1}\right.$ ) when the sample contains chlorides (Figure $2 \mathrm{~b}$ ) is an indication of the presence of $A u^{\delta-}$ species. It is possible that the $A u^{\delta-}$ species has a lower ability to adsorb unsaturated molecules and/or to dissociate hydrogen, and as a consequence is responsible for lower catalytic activity. It is also possible that the $\mathrm{Au}^{\delta-}$ species stabilise reaction intermediates, such as the half hydrogenated alkene, leading to a decrease of the fraction of free gold sites and as a consequence of the activity. These two reasons may also explain the small difference of selectivity. A third explanation could be that if chlorides directly interact with gold surface, they would inhibit the access to the reactants. Some recent papers showed that halides can be adsorbed on metallic gold (27) and can suppress the adsorption of reactants on the particles surface (26). In any case, the presence of chlorine in samples modifies the electronic properties of gold as attested by the CO probe-molecule, and lowers the catalytic activity. Where these chlorine species are located and whether there is a direct relationship between electronic and catalytic properties of gold is still a matter of discussion.

\section{Conclusion}

This study on the selective hydrogenation of butadiene in the presence of an excess of propene confirms the former studies performed with alkadiene alone that gold is highly selective. The presence of a large amount of alkenes does not drastically modify the catalytic behaviour of gold. The main reason, which was investigated in this paper, is that even though butadiene adsorbs slightly more strongly on 
gold than propene as in the case of palladium, the reactivity is drastically different from that on palladium since there is no competition between the hydrogenation of butadiene into butenes and the hydrogenation of butenes and propene into alkanes. Over gold catalysts, these two hydrogenation reactions operate in two separate temperature ranges.

The results showed that the method of depositionprecipitation with urea leads to smaller gold particles, and to more active catalysts than anionic adsorption or impregnation. Moreover, even for the same gold particle size, depositionprecipitation with urea provides more efficient catalysts in selective hydrogenation, probably because of the smaller concentration of chlorine present in the samples.

It was also found that the catalytic behaviour does not depend on the nature of the support provided that the other parameters are identical: same preparation methods, gold loading and gold particle size. It does not depend either on the gold particle size at least within the range of size investigated ( 2 to $5 \mathrm{~nm}$ ) since the estimated TOF is almost constant.

\section{Acknowledgements}

The authors want to thank the CNRS and the World Gold Council for their financial support to Antoine Hugon's PhD grant.

\section{About the authors}

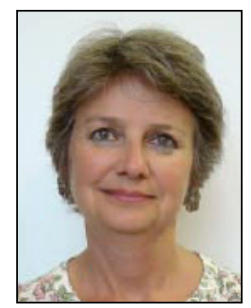

Catherine Louis is currently researcher at the French National Center for Scientific Research (CNRS) at the Laboratoire de Réactivité de Surface (LRS). Her research focuses on the preparation of supported metal catalysts and on the understanding of the chemical phenomena occurring during catalyst preparation. She has been working on gold catalysts since 2000 . At LRS, she is the leader of a team entitled "Reactivity of Catalytic materials based on noble Metal and pseudo-Metals" comprising six permanent researchers. She is also the leader of the Group of Research "gold-nano" (see preface).

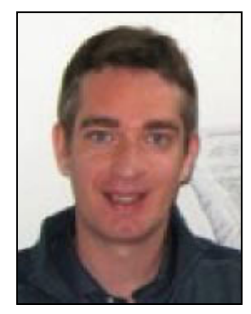

Laurent Delannoy is presently an Associate Professor in Inorganic Chemistry at the Pierre and Marie Curie University (UPMC - Paris 6). He received his PhD in Chemistry (Heterogeneous Catalysis) at the University of Science and Technology of Lille (France) in 2000. He joined the research group of Dr. Catherine Louis in 2002. His research interest involves the preparation and characterization of gold catalysts and the study of the performances of the gold catalysts in several hydrogenation and oxidation reactions.

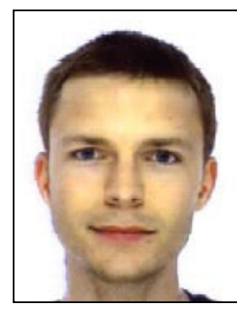

Antoine Hugon is a PhD student at LRS. He is now writing his thesis on selective hydrogenation of dienes over gold-based catalysts. His thesis was financially supported both by the CNRS and the WGC. He graduated as a chemical engineer from ESCOM, Ecole Supérieure de Chimie Organique et Minérale in 2003, where he studied organic chemistry and chemical engineering.

\section{References}

1 M.L. Derrien, Stud. Surf. Sci. Catal. 1986, 27, 613

2 T.V. Choudhary, C. Sivadinarayana, A. K. Datye, D. Kumar, D.W. Goodman, Cat. Lett. 2003, 86, 1

3 G.C. Bond, C. Louis, D. Thompson, Catalysis by Gold, Vol. 6, Imperial College Press, London, 2006

4 G.C. Bond, P. A. Sermon, G. Webb, D.A. Buchanan, P.B. Wells, Chem. Comm. 1973, 444

5 D.A. Buchanan, G. Webb, J. Chem. Soc. Faraday Trans. / 1975, 71, 134

6 M. Okumura, T. Akita, M. Haruta, Catal. Today2002, 74, 265

7 J. Jia, K. Haraki, J.N. Kondo, K. Domen, K. Tamatu, J. Phys Chem. B2000, 104, 11153

8 J.A. Lopez-Sanchez, D. Lennon, Appl. Cat. A 2005, 291, 230

9 Y. Segura, N. Lopez, J. Perez-Ramirez, J. Catal. 2007, 247, 383

10 J. Silvestre-Albero, G. Rupprechter, F. H.J., J. Catal. 2006, 240, 58

11 R. Zanella, S. Giorgio, C.R. Henry, C. Louis, J. Phys. Chem. B2002, 106, 7634

12 R. Zanella, L. Delannoy, C. Louis, Appl. Catal. A2005, 291, 62

13 A. Hugon, L. Delannoy, C. Louis, to be published

14 J.M. Fisher, Gold Bull. 2003, 36, 155

15 R. Zanella, C. Louis, Catal. Today 2005, 107-108, 768

16 A. Karpenko, R. Leppelt, V. Plzak, J. Cai, A. Chuvilin, B. Schumacher, U. Kaiser, R.J. Behm, Topics Catal. 2007, 44, 183

17 G. Bergeret, P. Gallezot, “Handbook on Heterogeneous Catalysis”, G. Ertl, H. Knözinger, J. Weitkamp (Eds), VCH, Weinheim, 1997, 2, 439

18 L. Delannoy, N. Weiher, N. Tsapatsaris, A.M. Beesley, L. Nchari, S.L.M. Schroeder, C. Louis, Topics Catal. 2007, 44, 263

19 F. Arena, P. Famulari, G. Trunfio, G. Bonura, F. Frusteri, L. Spadaro, Appl. Catal. B 2006, 66, 81

20 R. Zanella, C. Louis, S. Giorgio, R. Touroude, J. Catal. 2004, 223, 328

21 J.T. Miller, A.J. Kropf, Y. Zha, J.R. Regalbuto, L. Delannoy, C. Louis, E. Bus, J.A. van Bokhoven, J. Catal. 2006, 240, 222

22 C. Lemire, R. Meyer, S.K. Shaikhutdinov, H.J. Freund, Surf. Sci. 2004, 552, 27

23 Y. Jugnet, F.J. Cadete, C. Deranlot, L. Piccolo, J.C. Bertolini, Surf. Sci. 2002, 521, L639

24 J.D. Grunwaldt, M. Maciejewski, O.S. Becker, P. Fabrizioli, A. Baiker, J. Catal. 1999, 186, 458

25 F. Boccuzzi, A. Chiorino, M. Manzoli, D. Andreeva, T. Tabakova, J. Catal. 1999, 188, 176

26 S.M. Oxford, J.D. Henao, J.H. Yang, M.C. Kung, H.H. Kung, Appl. Catal. A 2008, 339, 180

27 T.A. Baker, C.M. Friend, E. Kaxiras, J. Am. Chem. Soc. 2008, 130, 3720

28 F. Boccuzzi, A. Chiorino, M. Manzoli, Surf. Sci. 2000, 454-456, 942 
29 M. Maciejewski, P. Fabrizioli, J.D. Grunwaldt, O.S. Becker, A. Baiker, Phys. Chem. Chem. Phys. 2001, 3, 3846

30 H. Klimev, K. Fajerwerg, K. Chakarova, L. Delannoy, C. Louis, K. Hadjiivanov, J. Mater. Sci. 2007, 42, 3299

31 S.H. Inami, B.J. Wood, H. Wise, J. Catal. 1969, 13, 397

32 A. Hugon, L. Delannoy, C. Louis, to be published

33 Q. Zhang, J. Li, X. Liu, Q. Zhu, Appl. Cat. A2000, 197, 221

34 B. Hammer, J.K. Norskov, Nature 1995, 376, 238

35 J. Harris, Surf. Sci. 1989, 221, 335

36 A.G. Sault, R.J. Madix, C.T. Campbell, Surf. Sci. 1986, 169, 347

37 M. Okada, M. Nakamura, K. Moritani, T. Kasai, Surf. Sci. 2003, 523, 218

38 L. Stobinski, L. Zommer, R. Dus, Appl. Surf. Sci. 1999, 141, 319
39 E. Bus, J.T. Miller, J.A. v. Bokhoven, J. Phys. Chem. B2005, 109, 14581

40 X. Zhang, H. Shi, B.-Q. Xu, Angew. Chem. Int. Ed. 2005, 44, 7132

41 X. Zhang, H. Shi, B.-Q. Xu, Catal. Today2007, 122, 330

42 R.B. Moyes, P.B. Wells, J. Grant, N.Y. Salman, Appl. Catal. A2002, 229, 251

43 M.C. Kung, R.J. Davis, H.H. Kung, J. Phys. Chem. B2007, 111

44 J.C. Fierro-Gonzalez, B.C. Gates, Topics Catal. 2007, 44, 103

45 T.V.W. Janssens, B.S. Clausen, B.Hvolbæk, H. Falsig, C.H. Christensen, T. Bligaard, J.K. Nørskov, Topics Catal. 2007, 44, 15

46 C. Louis, in Nanoparticles and Catalysis (Ed.: D. Astruc), Wiley-VCH, 2007

47 M. Haruta, Stud. Surf. Sci. Catal. 1997, 110, 123

48 N. Lopez, T.V.W. Janssens, B.S. Clausen, Y. Xu, M. Mavrikakis, T. Bligaard, J.K. Nørskov, J. Catal. 2004, 223, 232 